\title{
Managing Dry Eye Disease and Facilitating Realistic Patient Expectations: A Review and Appraisal of Current Therapies
}

This article was published in the following Dove Press journal: Clinical Ophthalmology

\author{
Bridgitte Shen Lee' \\ Alan G Kabat iD ${ }^{2}$ \\ Jason Bacharach ${ }^{3}$ \\ Paul Karpecki ${ }^{4}$ \\ Jodi Luchs iD ${ }^{5}$ \\ 'Vision Optique, Houston, TX, USA; \\ ${ }^{2}$ Pennsylvania College of Optometry, \\ Elkins Park, PA, USA; ${ }^{3}$ Florida Eye \\ Microsurgical Institute, Boynton Beach, \\ FL, USA; ${ }^{4}$ Kentucky Eye Institute, \\ Lexington, KY, USA; ${ }^{5}$ Florida Vision \\ Institute, West Palm Beach, FL, USA
}

\begin{abstract}
Dry eye disease (DED) is a multifactorial disease of the ocular surface characterized by loss of homeostasis of the tear film and accompanied by ocular signs and symptoms such as corneal and conjunctival damage, patient discomfort, and visual disturbance. The prevalence of DED ranges from 5\%-33\%. Patients with DED may have a reduced quality of life due to their discomfort and visual disturbances. The multifactorial nature of DED requires a multi-targeted treatment approach to address the signs and symptoms. Treatment for DED should follow a stepwise approach beginning with education, dietary modification, and lid and lash hygiene, and progressing to pharmacologic and nonpharmacologic interventions. Ocular lubricants, a mainstay of DED therapy, provide temporary symptomatic relief for the patient, but do not address the underlying pathophysiology. Some currently available pharmacologic treatments that address the underlying pathophysiology of DED may have a delay of 3-6 months in the onset of therapeutic effect; however, these treatment options may also have tolerability issues. These challenges highlight the need for newer pharmacologic treatments with an earlier onset of observable clinical effect and the potential for improved tolerability profile. Patient education is vital to DED management and should convey the complex and chronic nature of DED. It is important for the eye care practitioner to set realistic expectations with the patient when managing DED to help improve treatment success. This helps the patient understand the need for ongoing treatment and that results will likely not be seen immediately. This review covers the current management of DED, focusing on pharmacologic management, and offers recommendations for the practitioner to help facilitate realistic patient expectations for the treatment of DED.
\end{abstract} Keywords: OTX-101, dry eye disease, nanomicelles, drug delivery

\section{Introduction}

Dry eye disease (DED), also called keratoconjunctivitis sicca, is a multifactorial disease of the ocular surface characterized by loss of homeostasis of the tear film, and accompanied by symptoms such as ocular discomfort and visual disturbance. ${ }^{1}$ The reported prevalence of DED estimates vary widely, from $5 \%$ to $33 \%$, which may reflect both differing populations and inconsistent diagnostic criteria. ${ }^{2}$ Patients with moderate-to-severe DED may experience a reduced quality of life due to ocular pain, difficulty in performing daily activities, and depression. ${ }^{2}$ There is also a significant societal cost, both indirect (eg, reduced work productivity) and direct (eg, treatment costs). ${ }^{2}$

Many patients believe that once they begin treatment for DED, they will see an immediate improvement in their symptoms. It is essential that the eye care
Correspondence: Bridgitte Shen Lee Vision Optique, 5158 Buffalo Speedway, Houston, TX 77005, USA

$\mathrm{Tel}+$ I 7/3-838-2020

Email bshenlee@gmail.com 
practitioner helps the patient understand the need for ongoing treatment, and that results will likely not be seen immediately. The patient also needs to be instructed that there may be adverse events from the treatment itself, such as instillation site pain. This review discusses the etiology of DED, as well as recommendations for management of DED and the limitations encountered in the current treatment for DED, and finally, how to facilitate realistic patient expectations for the treatment of DED.

\section{Etiology and Nature of DED}

The revised Tear Film \& Ocular Surface Society Dry Eye Workshop (TFOS DEWS) II consensus definition highlights key pathophysiological drivers, defining DED as

a multifactorial disease of the ocular surface characterized by a loss of homeostasis of the tear film, and accompanied by ocular symptoms, in which tear film instability and hyperosmolarity, ocular surface inflammation and damage, and neurosensory abnormalities play etiological roles. ${ }^{1}$

The central mechanism of DED may be either evaporative tear loss or inadequate aqueous production, or a combination of both, which leads to hyperosmolarity, inflammation, and tissue damage. ${ }^{3}$ Subsequent development of punctate epitheliopathy and tear film instability leads to early tear film breakup, which exacerbates hyperosmolarity and results in the "vicious cycle" of DED. ${ }^{3}$

The 2 classifications of DED are aqueous-deficient dry eye and evaporative dry eye, which exist on an overlapping continuum. ${ }^{1}$ Aqueous-deficient dry eye is due to hyperosmolarity from reduced lacrimal secretions and is associated with conditions affecting lacrimal gland function (eg, Sjögren syndrome), while evaporative dry eye may result from meibomian gland dysfunction (MGD) or other eyelid-related and ocular surface-related causes. ${ }^{1,3}$ In addition to underlying medical conditions such as MGD, Sjögren syndrome, and connective tissue disorders, established population risk factors for DED include demographic features such as increasing age, female sex and race, androgen deficiency, environmental conditions, digital device use, medication use, and contact lens wear. ${ }^{2}$ Other risk factors may include cosmetics use, societal beauty trends, and various medical and aesthetic procedures, including laser-assisted in situ keratomileusis (LASIK), use of continuous positive airway pressure (CPAP) masks, botulinum toxin application, and eyelash growth enhancements. ${ }^{4}$
Discordance often exists between symptoms and signs of DED. Clinical tests used to diagnose DED include a combination of subjective and objective assessments such as questionnaires, tear breakup time, tear osmolarity, inflammatory marker expressions, ocular surface staining, and eyelid aspects such as blepharitis and Demodex. ${ }^{5}$ Understanding this discordance may provide useful information to guide the eye care practitioner in diagnosing and developing individualized treatment plans. ${ }^{6,7}$

\section{Recommendations for Management and Therapy}

TFOS DEWS II recommends individualized management of DED based on the relative contribution of aqueousdeficient and evaporative pathophysiology (to the extent that this can be determined), as well as disease severity. ${ }^{1}$ Treatment for DED progresses in a stepwise approach starting with education, dietary modification, lid hygiene, the use of lubricating eye drops, and modification of environmental factors, and progresses to nonpharmacologic and pharmacological management (Table 1). ${ }^{1}$ The multifactorial nature of DED requires a multi-targeted treatment approach from the lids and lashes to the tear film; one treatment does not replace another, although some treatments may target multiple aspects of a DED presentation. ${ }^{1}$ A medication review is necessary to identify systemic and topical medications that may contribute to DED (Table 2). ${ }^{1}$ For patients with early-stage DED, conventional, low-risk and widely available therapies such as warm compresses and over-the-counter artificial tears or other ocular lubricants may be used as first-line treatment. ${ }^{1}$ Lid hygiene includes detergent-based cleaning products and microblepharoexfoliation procedure to help remove lid margin debris and scurf, saline hygiene solution containing $0.01 \%$ pure hypochlorous acid to reduce biofilm, and warm compresses or lid hyperthermia to soften meibum and to facilitate its egress from the ducts.

If ocular lubricants and/or lid hygiene are inadequate to treat DED, then nonpharmacologic treatments may be used in conjunction with prescription medications. Prescription medications may include limited-duration topical corticosteroids, topical cyclosporine, and the lymphocyte function-associated antigen (LFA)-1 antagonist, lifitegrast; low-dose, oral tetracycline antibiotics may also be given for their anti-inflammatory effects in DED. ${ }^{1}$

Devices that may be used for tear conservation or stimulation include punctal occlusion, moisture goggles, and 
Table I DEWS II Recommended Staged Management Algorithm for Dry Eye Disease

\begin{tabular}{|c|c|}
\hline Step & Treatments \\
\hline Step I & $\begin{array}{l}\text { - Educate patient regarding } \\
\text { - Management } \\
\text { ○ Potential dietary modifications } \\
\text { - Treatment } \\
\text { - Prognosis } \\
\text { - Modify local environment } \\
\text { - Identify and modify or eliminate offending systemic and } \\
\text { - topical medications } \\
\text { - Administer warm compresses } \\
\text { - Perform lid hygiene and warm compresses }\end{array}$ \\
\hline Step 2 & $\begin{array}{l}\text { If options in Step I are inadequate: } \\
\text { - Administer } \\
\circ \text { Nonpreserved ocular lubricants } \\
\circ \text { Tea tree oil treatment for Demodex (if present) } \\
\circ \text { Overnight treatments } \\
\circ \text { Moisture chamber devise } \\
\circ \text { Ointments } \\
\circ \text { Prescription medications } \\
\circ \text { Topical antibiotic or antibiotic/steroid combination } \\
\circ \text { Topical corticosteroid } \\
\circ \text { Topical nonglucocorticoid immunomodulatory } \\
\text { drug (such as cyclosporine) } \\
\circ \text { Topical LFA-I antagonist drug (such as lifitegrast) } \\
\circ \text { Oral macrolide or tetracycline antibiotic } \\
\text { - Conserve tears using punctal occlusion or moisture } \\
\text { chamber goggles } \\
\text { - Perform in-office therapies } \\
\circ \text { Intense pulsed light therapy } \\
\circ \text { Meibomian gland expression }\end{array}$ \\
\hline Step 3 & $\begin{array}{l}\text { If options in Steps I and } 2 \text { are inadequate: } \\
\text { - Administer } \\
\text { - Oral secretagogues } \\
\text { - Autologous/allogeneic serum eye drops } \\
\text { - Use therapeutic contact lens } \\
\text { - Soft bandage lenses } \\
\text { - Rigid scleral lenses }\end{array}$ \\
\hline Step 4 & $\begin{array}{l}\text { If options in previous steps are inadequate: } \\
\text { - Administer topical corticosteroids for longer duration } \\
\text { - Perform surgical options } \\
\text { - Amniotic membrane graft } \\
\text { - Surgical punctal occlusion } \\
\text { - Tarsorrhaphy } \\
\text { - Salivary gland transplantation }\end{array}$ \\
\hline
\end{tabular}

Abbreviations: DEWS II, Dry Eye Workshop II; LFA-I, lymphocyte functionassociated antigen-I.

Notes: Adapted from Jones L, Downie LE, Korb D, et al. TFOS DEWS II management and therapy report. Ocul Surf. 2017;15:575-628. Copyright $\odot 2017$ Elsevier Inc. All rights reserved.'
Table 2 Selected Medications That May Cause or Aggravate Dry Eye Disease

\begin{tabular}{|l|l|}
\hline Systemic Drugs & Topical Drugs \\
\hline NSAIDs & Agents used to treat glaucoma \\
Diuretics & Beta-blocking agents \\
Vasodilators & Adrenergic agonist drugs \\
Analgesics/antipyretics & Carbonic anhydrase \\
Antiulcer agents & inhibitors \\
Sulfonylureas & Cholinergic agents \\
Cardiac glycosides & Prostaglandins \\
Anxiolytics/benzodiazepines & Agents used to treat allergies \\
Anti-infectives & Antiviral agents \\
Antidepressants/antipsychotics & Decongestants \\
Antihypertensives & Miotics \\
Antihistamines & Mydriatics and cycloplegics \\
Inhaled steroids & Preservatives \\
Systemic corticosteroids & Topical and local anesthetics \\
Systemic hormones (women $<50 y r)$ & Topical ocular NSAIDs \\
Hormone replacement therapy & \\
Antiandrogen therapy/medications & \\
Multivitamins & \\
\hline
\end{tabular}

Abbreviations: NSAID, nonsteroidal anti-inflammatory drug.

Note: Systemic drugs listed are limited to those found in large epidemiological studies to increase the risk of dry eye disease. Data from the prescibing information; Gomes et al. ${ }^{4}$

intranasal tear stimulation (eg, TrueTear ${ }^{\circledR}$, Allergan, Pleasanton, CA). Meibomian gland dysfunction may be treated by meibomian gland expression and devices such as vectored thermal pulsation therapy (eg, LipiFlow ${ }^{\circledR}$, Johnson \& Johnson Vision, Jacksonville, FL), intense pulsed light (IPL, eg, Optima IPL M22, Lumenis, Salt Lake City, UT), light-based heat and compression (eg, iLux, Alcon, Fort Worth, TX), and open-eye wearable thermal energy therapy (eg, TearCare, Sight Sciences, Menlo Park, CA). ${ }^{1}$ Punctal plugs intended for long-term use are typically silicone-based, but also include thermolabile polymer and hydrogel devices that conform to the shape of the canaliculus on insertion. ${ }^{1}$ Therapeutic contact lenses (soft "bandage" lenses or hard, gas-permeable scleral lenses) also help to conserve tears and are recommended for severe DED. ${ }^{1}$ The third step of care also includes oral secretagogues and autologous or allogeneic serum eye drops, while step 4 includes topical corticosteroids for longer durations, amniotic membrane grafts, surgical punctal occlusion, and more complex surgical approaches. ${ }^{1}$

For all management strategies, careful follow-up and detailed patient instructions are important to determine whether patients are consistently implementing the 
recommended approaches and to assess improvement in symptoms and/or signs. With the exception of topical cyclosporine, any improvement is likely to occur within the first few months, reflecting the typical study treatment duration in DED. ${ }^{1}$

\section{Limitations of Current DED Treatment}

At present, there is no cure for DED and ongoing management is needed. ${ }^{1}$ Treatment satisfaction was surveyed in more than 2000 health professionals with DED (mean duration, 10.1-10.5 years) who participated in the Women's Health Study and the Physicians' Health Studies I and II. ${ }^{8}$ Women reported higher frequency, severity, and impact of DED symptoms vs men and were significantly more likely to use artificial tears, topical cyclosporine, and omega fatty acid supplements, and undergo punctal occlusion. Overall, respondents were generally satisfied with treatment efficacy, ease of use, and convenience, but less satisfied with the time to symptom relief. ${ }^{8}$ After adjusting for age, women were significantly more dissatisfied than men with the time to symptom relief and with treatment side effects. ${ }^{8}$ A follow-up study evaluated patient-reported changes in DED since diagnosis. Improvement was reported by $44 \%$ of respondents for ocular surface symptoms, 19\% for vision-related symptoms, and $19 \%$ for social impact, while worsening since diagnosis was reported by $24 \%$, $29 \%$, and $10 \%$, respectively. ${ }^{9}$

While ocular lubricants are a mainstay of DED therapy, they generally provide only temporary symptom relief and do not target the underlying pathophysiology of DED. ${ }^{1}$ Numerous formulations are available. Those with high viscosity have improved retention time on the ocular surface compared to low viscosity drops, but may cause transient visual disturbances and accumulation of debris on the eyelids and lashes; therefore low viscosity drops are typically used during the day. ${ }^{1}$

Multidose formulations typically contain preservatives, which may have negative effects on the ocular surface after repeated exposure. ${ }^{1}$ A Cochrane review of artificial tears in 43 randomized controlled trials that included 3497 participants found most formulations may produce similar symptom relief, although more evidence is needed, especially for lipid-containing formulations. ${ }^{10,11}$ Cyclosporine ophthalmic emulsion $0.05 \%$ (Restasis ${ }^{\circledR}$, Allergan, Irvine, CA), a currently marketed pharmacologic treatment for DED, is indicated to increase tear production in patients whose tear production is presumed to be suppressed due to DED. ${ }^{12}$ Topical cyclosporine $0.05 \%$ significantly improved signs of DED after 21 weeks of use in most randomized controlled trials, with less consistent findings for symptom improvement. ${ }^{13}$

Approved in the US in 2016, lifitegrast ophthalmic solution is the only LFA-1 antagonist indicated for DED. ${ }^{14}$ In clinical trials, lifitegrast improved corneal staining after 6 weeks and the feeling of eye dryness vs placebo after 84 days. In a 1 -year safety study of lifitegrast, $15 \%$ of patients receiving the study drug had an adverse event of instillation site irritation, $13.2 \%$ experienced instillation site reaction, $11.4 \%$ noted decreased visual acuity, and $16.4 \%$ of patients complained of dysgeusia. ${ }^{15}$ Most patients reported these adverse events as "mild". ${ }^{15}$

Although studies report high rates of patient satisfaction and intention to continue treatment, health claims data reveal patients only fill an average of 4.4 months of dry eye medication over a 12 -month period. ${ }^{16}$ Ocular burning leads to discontinuation in a minority of patients and the reported time to onset of symptom relief ranges from 3 to 5 weeks to 3 months. ${ }^{16}$ These limitations may relate to lipophilic and hydrophobic drugs in oil-in-water emulsions (eg, cyclosporine) having low penetration into the ocular tissues; this has led to sustained efforts to enhance the delivery of the drug for topical administration. ${ }^{17}$

In August 2018, the Food and Drug Administration approved OTX-101 0.09\% (CEQUA ${ }^{\mathrm{TM}}$, Sun Pharmaceutical Industries, Inc., Cranbury, NJ) to increase tear production in patients with keratoconjunctivitis sicca ${ }^{18}$ OTX-101 is a novel, aqueous, nanomicellar ophthalmic solution of cyclosporine in a preservative-free, aqueous solution (Table 3). ${ }^{18}$ The selfassembling molecular aggregates encapsulate the lipophilic molecule (CsA) within a hydrophobic core, with an outer hydrophilic shell which helps to improve the solubility and bioavailability of the active ingredient in ocular tissues, with negligible systemic exposure. ${ }^{19,20}$ In a Phase IIb/III and a Phase III randomized controlled trials, OTX-101 demonstrated increased tear production compared with vehicle at 12 weeks ( $\mathrm{P}=0.0003$ and $\mathrm{P}<0.0001$, respectively), with improvements in ocular staining assessments beginning at 4 weeks after treatment initiation. ${ }^{21-23}$ Overall, $15 \%$ of patients receiving OTX-101 $0.09 \%$ vs $3 \%$ receiving vehicle experienced instillation site pain in the Phase IIb/III study, and 24\% vs $4 \%$ of patients, respectively, in Phase III study. Most patients in both studies reported the instillation site pain as "mild". 21,23 
Table 3 Comparison of Cyclosporine A 0.05\% Ophthalmic Emulsion and Cyclosporine A 0.09\% Ophthalmic Solution

\begin{tabular}{|c|c|c|}
\hline & Cyclosporine A $0.05 \%$ Ophthalmic Emulsion & Cyclosporine A $0.09 \%$ Ophthalmic Solution \\
\hline Formulation & Oil-in-water & Polymeric nanomicelles approved for ocular use \\
\hline Active ingredient & Cyclosporine A $0.05 \%$ & Cyclosporine A $0.09 \%$ \\
\hline Inactive ingredients & $\begin{array}{l}\text { Glycerin } \\
\text { Castor oil } \\
\text { Polysorbate } 80 \text { (surfactant) } \\
\text { Carbomer copolymer type A } \\
\text { Purified water } \\
\text { Sodium hydroxide to adjust pH }\end{array}$ & $\begin{array}{l}\text { HCO-40 (hydrogenated castor oil-40) } \\
\text { Octoxynol-40 } \\
\text { Sodium phosphate monobasic } \\
\text { PVP-K90 } \\
\text { Sodium phosphate dibasic } \\
\text { Purified water } \\
\text { Sodium hydroxide to adjust pH }\end{array}$ \\
\hline Osmolarity & $230-320 \mathrm{mOsmol} / \mathrm{kg}$ & $160-190 \mathrm{mOsmol} / \mathrm{kg}$ \\
\hline $\mathrm{pH}$ & $6.5-8.0$ & $6.5-7.2$ \\
\hline Appearance & White opaque to slightly translucent & Clear, uncolored solution \\
\hline Dosage regimen & Twice daily & Twice daily \\
\hline Key adverse events & $\begin{array}{l}\text { Burning eye }(14.7 \%) \\
\text { Stinging eye }(3.4 \%) \\
\text { Eye discharge }(3.1 \%) \\
\text { Conjunctival hyperemia }(2.0 \%) \\
\text { Eye pain }(1.0 \%)\end{array}$ & $\begin{array}{l}\text { Instillation site pain }(24.2 \%) \\
\text { Conjunctival hyperemia }(8.1 \%) \\
\text { Instillation site lacrimation (I.I\%) } \\
\text { Instillation site reaction (I.1\%) } \\
\text { Eye irritation }(0.8 \%)\end{array}$ \\
\hline
\end{tabular}

Note: Data from the prescribing information; references 12 and 18.

\section{Facilitating Realistic Patient Expectations for the Treatment of Dry Eye Disease}

Patient education is vital to DED management and should convey the complex and chronic nature of DED as well as the potential for progression. The patient must understand the need for ongoing treatment, and that results will likely not be seen immediately. Lifestyle changes are also important considerations. Careful questioning will help the patient identify possible factors contributing to their DED and allow creation of a customized treatment plan that is likely to be followed and increase the potential for treatment success.

Approximately $80 \%$ of American adults report using digital devices for $>2$ hrs per day, and nearly $67 \%$ using 2 or more devices simultaneously; 59\% report experiencing symptoms of digital eye strain (DES). ${ }^{24}$ The most common DES symptoms are eye fatigue, dry eyes, headaches, neck and shoulder pain, and blurred vision. ${ }^{25}$ Prevention of DES symptoms should be discussed, including straightforward strategies such as preservative-free lubricating drops, blinking exercises, digital device positioning, and the need for regular breaks. ${ }^{7}$ Anti-fatigue ophthalmic lens designs often provide relief in patients who report eye strain symptoms. Contact lens patients with dry eye symptoms may find increased comfort with premium siliconehydrogel 1-day disposable contact lenses, but will often require simultaneous treatment of the underlying dry eye disease when present. ${ }^{26}$ Patients with poor tear film quality and who are symptomatic with visual discomfort glare from light-emitting diode (LED)-powered office lights, digital devices, vehicle headlights, and sports fields may find relief with prescription anti-glare and blue light protection ophthalmic lens treatment.

Local environmental modifications that may be beneficial include avoiding exposure to desiccating conditions and environmental pollutants, including tobacco smoke. ${ }^{1}$ In practical terms, this might involve redirecting air vents, avoiding hairdryer use, using a desktop humidifier, or wearing wraparound sunglasses.

Cosmetic product use and ingredients should also be reviewed. Retinoids in anti-aging creams applied around the eye have negative effects on the meibomian glands and can contribute to DED. Likewise, eye makeup should only be applied to the outer eyelash line to reduce its migration to the ocular surface. ${ }^{4,27,28}$ Thorough removal of eye makeup is needed to avoid products blocking the meibomian glands or 
the occurrence of blepharitis; metallic or glittery eye products or any eye makeup that flakes should be avoided by patients with DED. ${ }^{29,30}$ Eyelash-enhancing serums that contain synthetic prostaglandin (isopropyl cloprostenate) should be avoided in patients with MGD and DED signs and/or symptoms. In addition, eyelash extensions, false eyelashes, and eyelash tinting and lifting practices can cause various ocular surface disease symptoms. $^{4}$

Dietary modification to treat DED has been the focus of considerable research, notably with respect to essential fatty acid supplementation (eg, omega-3, omega-6/gamma linolenic acid, or both). ${ }^{1}$ While positive results have been obtained, results have been inconsistent, and most trials have short treatment durations. ${ }^{1}$ The randomized, doublemasked, Dry Eye Assessment and Management (DREAM) study found no significant benefit after 12 months for high-dose omega-3 supplementation (3000 mg of fishderived n-3 eicosapentaenoic and docosahexaenoic acids) compared with an olive oil placebo in over 500 patients with moderate-to-severe $\mathrm{DED} ;{ }^{31}$ however, interpretation of the findings is complicated by questions over the positive effects of olive oil and unrestricted use of other DED treatments during the trial, which was designed to mimic a real-world setting. Increasing fluid intake to ensure adequate general hydration may improve DED symptoms, as even modest whole-body dehydration during exercise increases tear osmolarity in healthy adults; individuals with DED have higher plasma osmolality than those without DED. ${ }^{1}$ Conversely, alcohol intake induces transient signs of DED in healthy individuals, suggesting that consumption may worsen the signs and symptoms of DED. ${ }^{32}$ Regarding complementary medicine, there is some clinical trial evidence that supports the use of traditional Chinese herbs and acupuncture or related procedures in patients with DED, while preliminary investigations suggest that reducing calorie intake and body fat may be beneficial. ${ }^{33,34}$

Management of DED may require more than 1 therapeutic modality, including treatment to reduce inflammation in addition to treatments for MGD, blepharitis, Demodex, and/or tear film instability. For each selected modality, the mechanism of action, goals of treatment, and expected treatment duration should be clearly explained in terms that can be easily understood by the patient. In addition, patients find it helpful to know the sequence of what DED treatment to perform during their morning and evening routines, and appreciate a detailed written treatment plan that includes the sequence of actions for both DED treatment and their skincare routine. Treatment costs, health insurance coverage, and the challenges of adherence to a complex regimen are additional considerations.

The inflammatory component of DED often requires prescription intervention, and when it does, patients need to continue treatment even after they obtain symptomatic relief. Patients should be instructed in the correct technique for drop instillation. It may be helpful to explain that some patients experience stinging or an altered sense of taste (dysgeusia), which should not be grounds for concern. The burning sensation that can be associated with topical cyclosporine may be reduced by cold administration (ie, refrigerating the medication) or by giving topical corticosteroids prior to initiation of cyclosporine. ${ }^{17}$ Various topical formulations of cyclosporine display some degree of instillation site irritation, although this phenomenon does not appear to be concentrationdependent. ${ }^{13,21,23,35,36}$ Numerous factors can contribute to discomfort from ophthalmic drug instillation, including the vehicle, $\mathrm{pH}$, osmolarity, and presence of inactive ingredients and preservatives. More importantly however, the immediate discomfort after instillation often decreases over time with continued use. ${ }^{37}$ Patients must be educated to this fact and encouraged to persevere with treatment for maximal benefit. Self-reported adherence with the prescribed twice-daily regimen of topical cyclosporine $0.05 \%$ was associated with more rapid onset of reported increase in tear production, as well as greater patient satisfaction and willingness to continue therapy. ${ }^{38}$

\section{Conclusion}

Despite the broader understanding of DED that we enjoy today and the advent of numerous, multimodal forms of therapy, there are still many challenges and limitations. Some of the current limitations of DED therapy may be addressed by new treatment options such as OTX-101. These newer options may help decrease the time to symptom relief, providing the patient with an incentive for treatment continuation. New treatment options may also have a favorable tolerability profile, which may enhance patient persistence. By addressing the limitations of the current pharmacologic therapies, new therapeutic options may help eye care practitioners more effectively treat and manage DED.

Managing DED appropriately and facilitating realistic patient expectations are necessary to ensure patient satisfaction and compliance with their treatment. Practitioners should explain the etiologies of the condition in clear and comprehensible terms, as well as the goals and expected length of time for all therapies prescribed. Moreover, eye care 
practitioners need to emphasize that the interventions may be slow to yield results, and that therapy must be continued even after the symptoms have improved. These are the cornerstones of successfully managing patients with DED.

\section{Acknowledgment}

Editorial assistance was provided by Jennifer Meyering, RN, MS, CMPP (AlphaBioCom, LLC, King of Prussia, PA).

\section{Funding}

Editorial assistance was funded by Sun Pharmaceutical Industries, Inc (Princeton, NJ).

\section{Disclosure}

AK reports consultant fees from Bio-Tissue, Kala Pharmaceuticals, Inc., Lacrivera, Shire, OCuSOFT, and Vmax; speaker fees from Shire and Quidel; and personal fees from Avellino, Bruder Healthcare, Inc., EyeGate, Sight Sciences, and Sun Pharmaceutical Industries, Inc.; and nonfinancial support from Sun Pharmaceutical Industries, Inc., during the conduct of the study; grants and personal fees from Bio-Tissue, Inc.; and personal fees from Avellino Labs, Bruder Healthcare, Inc., EyeGate Pharma, Kala Pharmaceuticals, Inc., Lacrivera, MacuLogix, National Vision Administrators, LLC, OCuSOFT, Quidel, Shire, Sight Sciences, Sun Pharmaceutical Industries, Inc., personal fees from Takeda, personal fees from TearScience, grants, personal fees, non-financial support from Vmax Vision, outside the submitted work. BSL reports consultant fees from Alcon, Guardian Health Sciences, Johnson \& Johnson Vision, Lumenis, OCuSOFT, and Sun Pharmaceutical Industries, Inc.; and personal fees from Alcon, EyeVanceJohnson \& Johnson Vision,Lumenis, OCuSOFT, Shire, and Sun Pharmaceutical Industries, Inc., outside the submitted work. JB reports speaker fees from Aerie, Alcon, Allergan, Bausch \& Lomb, Glaukos, New World Medical, and Sun Pharmaceutical Industries, Inc.; and consultant fees from Aerie, Alcon, Allergan, Bausch \& Lomb, Injectsense, New World Medical, and Optovue; and additional personal fees from Sun Pharmaceutical Industries, Inc, outside the submitted work. JL reports personal fees from Allergan, Alcon, Bausch \& Lomb, Shire, Sun Pharmaceutical Industries, Inc., and Tear Lab; and additional fees from Allergan, Alcon, Bausch \& Lomb, Calhoun Vision, CLXO, Insightful Solutions, Shire, Sun Pharmaceutical Industries, Inc., and Trefoil Therapeutics; and additional personal fees from Alcon, Allergan, Calhoun Vision, EyeVance, Ocular Sciences, RPS, Shire, Sun
Pharmaceutical Industries, Inc., ; and other personal fees from Bausch and Lomb, CXLO, Insightful Solutions, and Omega Ophthalmics, outside the submitted work. PK reports consultant fees from Aerie, Akorn, Alcon, Allergan, Allysta, Avellino Labs, Azura Pharmaceuticals, Bausch \& Lomb, BioTissue, BlephEx, Bruder Healthcare, Inc., Cambium, EyeBrain/Neurolens, EyeGate Pharma, EyeVance, Imprimis, Jobson Medical Information/Web MD, Johnson \& Johnson Vision, Nevakar, Novaliq, Oasis Medical, Ocular Sciences, Oculus, OcuMedic, OCuSOFT, Oyster Point Medical, Science Based Health, Sentiss; Sight Sciences, Silk Technologies, Sun Pharmaceutical Industries, Inc., Surface Pharmaceuticals, Tarsus Medical, Tear Lab, TopiVert, Visant Medical, and Vital Tears; and personal fees from Sun Pharmaceutical Industries, Inc. outside the submitted work. The authors report no other conflicts of interest in this work.

\section{References}

1. Jones L, Downie LE, Korb D, et al. TFOS DEWS II management and therapy report. Ocul Surf. 2017;15:575-628. doi:10.1016/j. jtos.2017.05.006

2. Stapleton F, Alves M, Bunya VY, et al. TFOS DEWS II epidemiology report. Ocul Surf. 2017;15:334-365. doi:10.1016/j.jtos.2017.05.003

3. Bron AJ, de Paiva CS, Chauhan SK, et al. TFOS DEWS II pathophysiology report. Ocul Surf. 2017;15:438-510. doi:10.1016/j. jtos.2017.05.011

4. Gomes JAP, Azar DT, Baudouin C, et al. TFOS DEWS II iatrogenic report. Ocul Surf. 2017;15:511-538. doi:10.1016/j.jtos.2017.05.004

5. Wolffsohn JS, Arita R, Chalmers R, et al. TFOS DEWS II diagnostic methodology report. Ocul Surf. 2017;15:539-574. doi:10.1016/j. jtos.2017.05.001

6. Ong ES, Felix ER, Levitt RC, Feuer WJ, Sarantopoulos CD, Galor A. Epidemiology of discordance between symptoms and signs of dry eye. Br J Ophthalmol. 2018;102:674-679. doi:10.1136/bjophthalmol2017-310633

7. Vehof J, Sillevis Smitt-Kamminga N, Nibourg SA, Hammond CJ. Predictors of discordance between symptoms and signs in dry eye disease. Ophthalmology. 2017;124:280-286. doi:10.1016/j.ophtha.2016. 11.008

8. Schaumberg DA, Uchino M, Christen WG, Semba RD, Buring JE, Li JZ. Patient reported differences in dry eye disease between men and women: impact, management, and patient satisfaction. PLoS One. 2013;8:e76121. doi:10.1371/journal.pone.0076121

9. Lienert JP, Tarko L, Uchino M, Christen WG, Schaumberg DA. Long-term natural history of dry eye disease from the patient's perspective. Ophthalmology. 2016;123:425-433. doi:10.1016/j. ophtha.2015.10.011

10. Pan Q, Angelina A, Marrone M, Stark WJ, Akpek EK. Autologous serum eye drops for dry eye. Cochrane Database Syst Rev. 2017;2:CD009327.

11. Pucker AD, Ng SM, Nichols JJ. Over the counter (OTC) artificial tear drops for dry eye syndrome. Cochrane Database Syst Rev. 2016;2: CD009729.

12. Restasis ${ }^{\circledR}$ (cyclosporine ophthalmic emulsion) $0.05 \%$, for topical ophthalmic use. Full prescribing information. Allergan, Irvine, CA. 2017.

13. Sall K, Stevenson OD, Mundorf TK, Reis BL. Two multicenter, randomized studies of the efficacy and safety of cyclosporine ophthalmic emulsion in moderate to severe dry eye disease. CsA Phase 3 Study Group. Ophthalmology. 2000;107:631-639. doi:10.10 16/S0161-6420(99)00176-1 
14. $\mathrm{Xiidra}^{\mathrm{TM}}$ (lifitegrast ophthalmic solution) $5 \%$, for topical ophthalmic use. Lexington, MA: Shire US, Inc.; 2016.

15. Donnenfeld ED, Karpecki PM, Majmudar PA, et al. Safety of lifitegrast ophthalmic solution $5.0 \%$ in patients with dry eye disease: a 1-year, multicenter, randomized, Placebo-controlled study. Cornea. 2016;35:741-748. doi:10.1097/ICO.0000000000000803

16. Deveney T, Asbell PA. Patient and physician perspectives on the use of cyclosporine ophthalmic emulsion $0.05 \%$ for the management of chronic dry eye. Clin Ophthalmol. 2018;12:569-576. doi:10.2147/OPTH

17. Lallemand F, Schmitt M, Bourges JL, Gurny R, Benita S, Garrigue JS. Cyclosporine a delivery to the eye: a comprehensive review of academic and industrial efforts. Eur J Pharm Biopharm. 2017;117:14-28. doi:10.1016/j.ejpb.2017.03.006

18. CEQUA ${ }^{\mathrm{TM}}$ (cyclosporine ophthalmic emulsion) $0.09 \%$. Full Prescribing Information. Cranbury, NJ, USA: Sun Pharmaceutical Industries, Inc.; 2018.

19. Cholkar K, Gilger BC, Mitra AK. Topical, aqueous, clear cyclosporine formulation design for anterior and posterior ocular delivery. Transl Vis Sci Technol. 2015;4:1. doi:10.1167/tvst.4.3.1

20. Vaishya RD, Khurana V, Patel S, Mitra AK. Controlled ocular drug delivery with nanomicelles. Wiley Interdiscip Rev Nanomed Nanobiotechnol. 2014;6:422-437. doi:10.1002/wnan.1272

21. Goldberg DF, Malhotra RP, Schechter BA, Justice A, Weiss SL, Sheppard JD. A Phase 3, randomized, double-masked study of OTX-101 ophthalmic solution $0.09 \%$ in the treatment of dry eye disease. Ophthalmology. 2019;126:1230-1237. doi:10.1016/j.ophtha. 2019.03.050

22. Malhotra R, Devries DK, Luchs J, et al. Effect of OTX-101, a novel nanomicellar formulation of cyclosporine $\mathrm{A}$, on corneal staining in patients with keratoconjunctivitis sicca: a pooled analysis of Phase 2b/3 and Phase 3 studies. Cornea. 2019;38:1259-1265. doi:10.1097/ ICO.0000000000001989

23. Tauber J, Schechter BA, Bacharach J, et al. A Phase II/III, randomized, double-masked, vehicle-controlled, dose-ranging study of the safety and efficacy of OTX-101 in the treatment of dry eye disease. Clin Ophthalmol. 2018;12:1921-1929. doi:10. 2147/OPTH

24. American Optometric Association. Computer vision syndrome; 2017. Available from: https://www.aoa.org/patients-and-public/caring-foryour-vision/protecting-your-vision/computer-vision-syndrome?sso=y. Accessed November 12, 2019.

25. The Vision Council. Eyes overexposed: the digital device dilemma: digital eye strain report; 2016. Available from: https://www.thevision council.org/content/digital-eye-strain. Accessed November 12, 2019.
26. Lubis RR, Gultom MTH. The correlation between daily lens wear duration and dry eye syndrome. Open Access Maced J Med Sci. 2018;6:829-834. doi:10.3889/oamjms.2018.215

27. Ng A, Evans K, North RV, Purslow C. Migration of cosmetic products into the tear film. Eye Contact Lens. 2015;41:304-309. doi:10.1097/ICL.0000000000000124

28. O’Dell L, Periman L, Sullivan A, Halleran C, Harthan J, Hom M. An evaluation of cosmetic wear habits correlated to ocular surface disease symptoms. Invest Ophthalmol Vis Sci. 2017;58(8):495.

29. Harthan J, O'Dell L, Halleran C, Schwartz S, Hom M. Impact of make-up on self-reported ocular comfort and meibomian gland atrophy. Am Acad Optometry. 2017.

30. Wang MT, Craig JP. Investigating the effect of eye cosmetics on the tear film: current insights. Clin Optom (Auckl). 2018;10:33-40. doi: $10.2147 /$ OPTO

31. Dry Eye A, Management Study Research G, Asbell PA, et al. N-3 fatty acid supplementation for the treatment of dry eye disease. N Engl J Med. 2018;378:1681-1690.

32. Kim JH, Kim JH, Nam WH, et al. Oral alcohol administration disturbs tear film and ocular surface. Ophthalmology. 2012;119:965-971. doi:10.1016/j.ophtha.2011.11.015

33. Kawashima M, Nakamura S, Izuta Y, Inoue S, Tsubota K. Dietary Supplementation with a combination of lactoferrin, fish oil, and enterococcus faecium WB2000 for treating dry eye: a rat model and human clinical study. Ocul Surf. 2016;14:255-263. doi:10.1016/j.jtos.2015.12.005

34. Kawashima M, Tsubota K. Effect of calorie restriction on change in lacrimal gland with age. Cornea. 2011;30(Suppl 1):S29-33. doi:10.1097/ICO.0b013e318228167f

35. Baudouin C, de la Maza MS, Amrane M, et al. One-year efficacy and safety of $0.1 \%$ cyclosporine A cationic emulsion in the treatment of severe dry eye disease. Eur $J$ Ophthalmol. 2017;27:678-685. doi:10.5301/ejo.5001002

36. Wirta DL, Torkildsen GL, Moreira HR, et al. A clinical Phase II study to assess efficacy, safety, and tolerability of waterfree cyclosporine formulation for treatment of dry eye disease. Ophthalmology. 2019;126:792-800. doi:10.1016/j.ophtha.2019.01.024

37. Deveci H, Kobak S. The efficacy of topical $0.05 \%$ cyclosporine A in patients with dry eye disease associated with Sjogren's syndrome. Int Ophthalmol. 2014;34:1043-1048. doi:10.1007/s10792-014-9901-4

38. Trattler W, Katsev D, Kerney D. Self-reported compliance with topical cyclosporine emulsion $0.05 \%$ and onset of the effects of increased tear production as assessed through patient surveys. Clin Ther. 2006;28:1848-1856. doi:10.1016/j.clinthera.2006.11.016
Clinical Ophthalmology

\section{Publish your work in this journal}

Clinical Ophthalmology is an international, peer-reviewed journal covering all subspecialties within ophthalmology. Key topics include: Optometry; Visual science; Pharmacology and drug therapy in eye diseases; Basic Sciences; Primary and Secondary eye care; Patient Safety and Quality of Care Improvements. This journal is indexed on PubMed
Central and CAS, and is the official journal of The Society of Clinical Ophthalmology (SCO). The manuscript management system is completely online and includes a very quick and fair peer-review system, which is all easy to use. Visit http://www.dovepress.com/ testimonials.php to read real quotes from published authors.

\section{Dovepress}

